\title{
Preliminary Investigation on Rotary Ultrasonic Face Milling of Ceramic Matrix Composite C/Sic: Design of Experiments
}

\author{
Jianjian Wang 1, 2, a, Qiaoli Zhang 1,2,c and Pingfa Feng 1, 3, b \\ ${ }^{1}$ Beijing Key Lab of Precision/Ultra-precision Manufacturing Equipment and Controls, Tsinghua \\ University, Beijing 100084, China \\ ${ }^{2}$ State Key Laboratory of Tribology, Department of Mechanical Engineering, Tsinghua University, \\ Beijing, 100084, China \\ ${ }^{3}$ Division of Advanced Manufacturing, Graduate School at Shenzhen, Tsinghua University, \\ Shenzhen 518055, China \\ awangjj11@foxmail.com, bfengpf@mail.tsinghua.edu.cn, c843024770@qq.com
}

Keywords: Rotary ultrasonic machining, Ceramic matrix composites, C/SiC.

\begin{abstract}
The feasibility of rotary ultrasonic face milling (RUFM) of ceramic matrix composites was evaluated experimentally in this study. Preliminary experimental results show that, comparing with conventional grinding (CG), RUFM can reduce cutting forces dramatically though with a little enlargement of surface roughness. Both in CG and RUFM, a positive dependency of surface roughness on cutting force can be deduced. For machining of $2 \mathrm{D}-\mathrm{C} / \mathrm{SiC}$ composites, the fiber direction significantly affects the cutting force and surface roughness. When fibers are parallel to the cutting plane, the cutting force and surface roughness are much larger than that when fibers are perpendicular to the cutting plane.
\end{abstract}

\section{Introduction}

Ceramic matrix composites (CMCs) such as $\mathrm{C} / \mathrm{SiC}$ have emerged as a novel strategic structure material in various industry areas such as astronautics, automobile and nuclear energy [1]. However, due to the existence of hard ceramic matrix, CMCs are regarded as typical difficult-to-machine materials. In order to improve the machining of $\mathrm{CMCs}$, various conventional and unconventional processing methods have been introduced, such as grinding [2], laser beam machining [3], rotary ultrasonic machining [4]. Rotary ultrasonic machining has been sufficiently proved to be suitable for the hole manufacturing of CMCs, with dramatically reduced cutting force and improved hole exit quality [4].

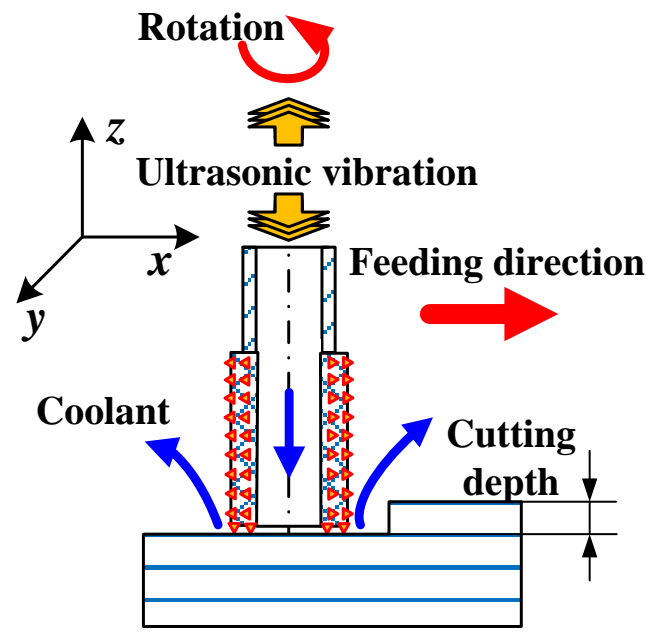

Fig. 1 Illustration of RUFM

This study tries to introduce the rotary ultrasonic machining to surface generating of CMCs. As illustrated in Fig.1, for surface machining, the rotary ultrasonic machining is also known as rotary ultrasonic face milling (RUFM). In RUFM, a rotating grinding wheel electroplated with diamond 
abrasives is vibrating ultrasonically when feeding towards to the workpiece [5]. The processing outputs such as cutting force and surface roughness will be compared with conventional grinding (CG) to evaluate the feasibility of RUFM for CMCs.

\section{Experimental design}

RUFM experiments were conducted on Ultrasonic 50 (DMG, Germany). The illustration of experiment apparatus is shown in Fig.2. The outer diameter of diamond tool was $50 \mathrm{~mm}$. The size of diamond abrasive was around $100 \mu \mathrm{m}$. Both inner and outer coolant were used simultaneously. The workpiece was a 2D-C/SiC composite panel. As shown in Fig.2, it has two kinds of plane: plane A and plane $\mathrm{B}$. When machining plane A, all fibers are parallel to the cutting plane. However, when machining plane B, some fibers are perpendicular to the cutting plane. The machining parameters are listed in Table 1. The ultrasonic frequency was about $17.8 \mathrm{kHz}$. The ultrasonic amplitude was $1 \sim 2 \mu \mathrm{m}$. When the ultrasonic mode of Ultrasonic 50 was shut down, the machining method was changed from RUFM to $\mathrm{CG}$.

The cutting forces were measured using a dynamometer (Kistler 9256C2, Switzerland). A SEM (QUANTA 200 FEG, FEI, Hillsboro, America) was used to inspect the machined surface. A 3D Optical Surface Profiler (NPFLEX, Bruker, Germany) was used to evaluate surface roughness $S_{\text {a }}$ avoiding the previously existing voids of $\mathrm{C} / \mathrm{SiC}$. The detailed of definition of $\mathrm{Sa}$ can be found from other researcher's article [6].

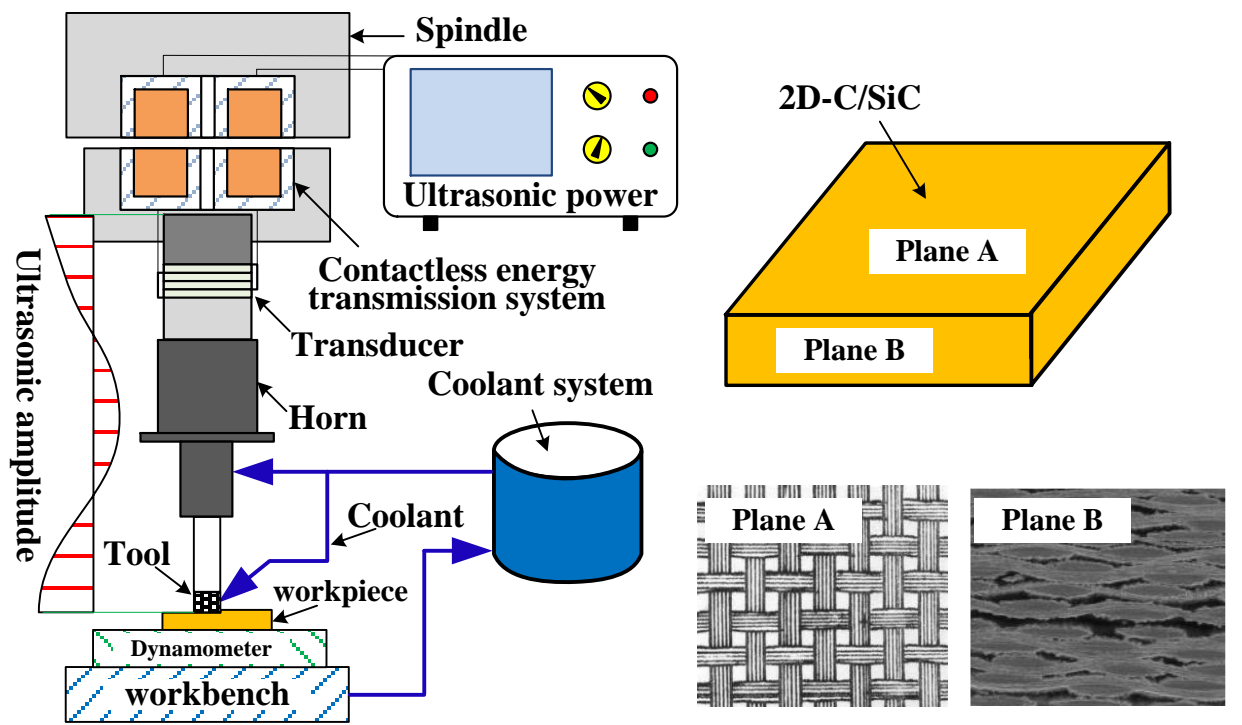

Fig. 2 Illustration of experiment apparatus and workpiece

Table 1. Design of machining parameters

\begin{tabular}{|c|c|c|c|c|}
\hline No. & Spindle speed $(\mathrm{rpm})$ & Feedrate $(\mathrm{mm} / \mathrm{min})$ & Cutting depth $(\mathrm{mm})$ & Machining method \\
\hline 1 & 500 & 5 & 0.02 & RUFM,CG \\
\hline 2 & 500 & 15 & 0.02 & RUFM,CG \\
\hline 3 & 500 & 15 & 0.05 & RUFM,CG \\
\hline 4 & 1000 & 5 & 0.02 & RUFM,CG \\
\hline
\end{tabular}

\section{Results and conclusion}

\subsection{Surface morphology.}

Fig.3 shows the typical surface morphology in RUFM of C/SiC. As shown in Fig.3, when machining plane B, no obvious difference between RUFM and CG can be distinguished from the surface morphology. Though when machining plane A, the surface morphology obtained by RUFM is similar to that obtained by CG. The distances between fiber fracture to fracture was comparable. As shown in 
Fig.3 (a) and Fig.3 (b), $L_{\text {RUFM }}<L_{\mathrm{CG}}$. This phenomenon was typical for various machining parameters. According to material removal mechanism in rotary ultrasonic machining of homogeneous brittle materials, the impact effects of ultrasonic vibration can prompt the generation of micro cracks resulting in the material removal of microchips mode [7]. The ultrasonic vibration of abrasives induced impact effect maybe also account for the above results about the distances between fiber fracture to fracture. By the way, the effect of various distances between fiber fracture to fracture on the working performance of workpiece should also be evaluated in the future research.

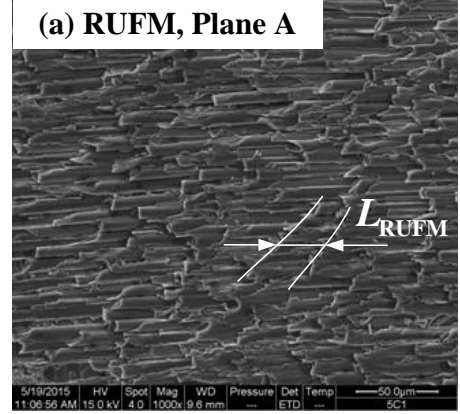

(c) RUFM, Plane B

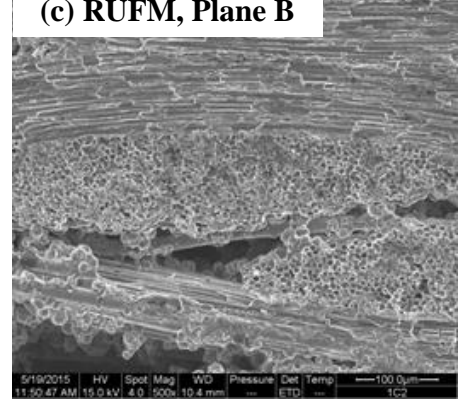

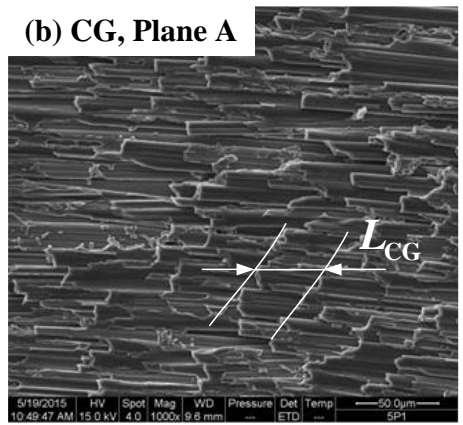

(d) CG, Plane B

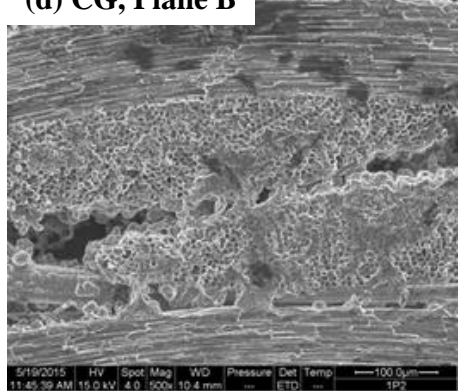

Fig. 3 Comparison of surface morphology

\subsection{Surface roughness and cutting forces.}

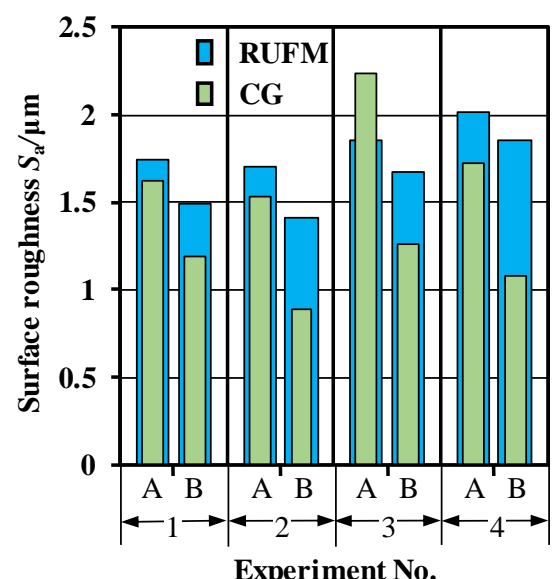

Experiment No.

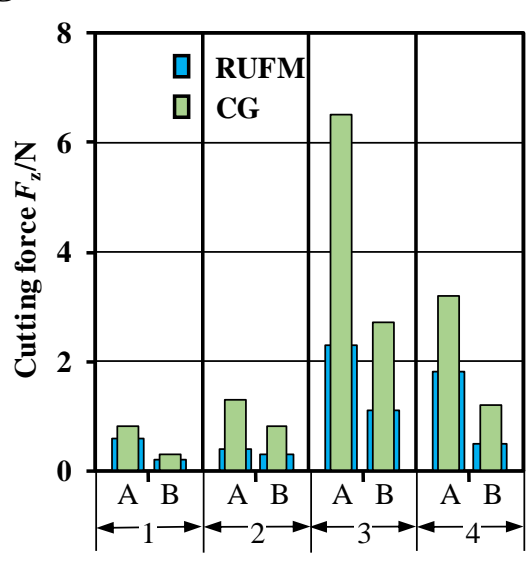

Experiment No.

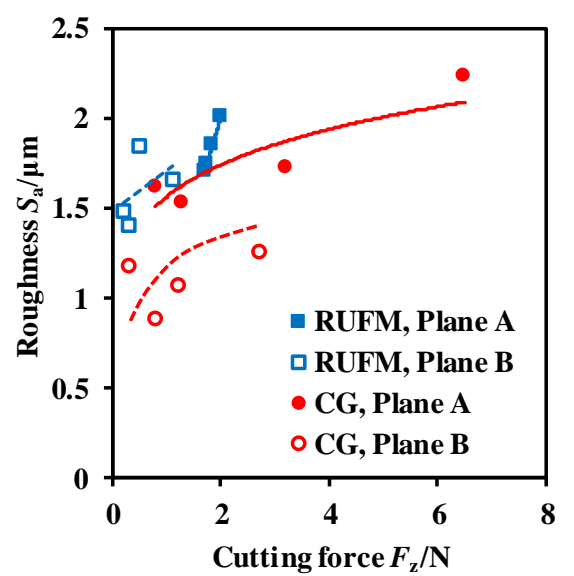

Fig. 4 Comparison of cutting force and surface roughness

Fig. 4 shows the comparison of cutting force and surface roughness between RUFM and CG. The labels of A and B represent plane A and plane B respectively. As shown in Fig.4, The cutting forces of RUFM were much smaller than that of CG. RUFM can reduce the cutting forces by an average of $50 \%$ comparing with CG. The significant reduction of cutting force in RUFM provides a possibility of machining efficiency improvement considering the potential suppression of tool wear. However, in terms of surface roughness, RUFM didn't show up any superiority than CG. The surface roughness $S_{\mathrm{a}}$ of RUFM were always larger than that of CG. This is consistent with the results of RUFM of homogeneous brittle materials [8]. Simultaneously, the fiber direction greatly affects the cutting forces and surface roughness. As shown in Fig.4, both the cutting forces and surface roughness $S_{\text {a }}$ when machining plane $\mathrm{B}$ were much smaller than these when machining plane A. Furthermore, a basically positive relationship between surface roughness and cutting force can be found as shown in Fig.4. This 
dependency of surface roughness on the cutting force provides a method for monitoring the surface roughness during the machining process.

\section{Summary}

(1) RUFM can reduce cutting forces dramatically though with a little enlargement of surface roughness for machining of $\mathrm{C} / \mathrm{SiC}$ composites. Both in CG and RUFM, a positive dependency of surface roughness on cutting force can be deduced. This can be used for the online monitoring of surface quality.

(2) For machining of $2 \mathrm{D}-\mathrm{C} / \mathrm{SiC}$ composites, the fiber direction significantly affects the cutting force and surface roughness. When fibers are parallel to the cutting plane, the cutting force and surface roughness are much larger than that when fibers are perpendicular to the cutting plane.

\section{References}

[1]. S. Schmidt, S. Beyer, H. Knabe, et al. Advanced ceramic matrix composite materials for current and future propulsion technology applications. Acta Astronautica. Vol. 55 (2004), p.409-420.

[2]. L. Zhang, C. Ren, C. Ji, Z. et al. Effect of fiber orientations on surface grinding process of unidirectional C/SiC composites. Applied Surface Science. Vol. 366 (2016), p.424-431.

[3]. W. Li, R. Zhang, Y. Liu, C. Wang, J. Wang, X. Yang, Effect of different parameters on machining of SiC/SiC composites via pico-second laser. Applied Surface Science. Vol. 364 (2016), p.378-387.

[4]. Feng P, Wang J, Zhang J, et al. Drilling induced tearing defects in rotary ultrasonic machining of C/SiC composites. Ceramics International. Vol. 43 (2017) No. 1, 791-799.

[5]. Zhang C, Zhang J, Feng P, et al. Mathematical model for cutting force in rotary ultrasonic face milling of brittle materials. The International Journal of Advanced Manufacturing Technology. Vol. 69 (2013) No. 1-4, 161-170.

[6]. Li H, Lin B, Wan S, et al. An experimental investigation on ultrasonic vibration-assisted grinding of $\mathrm{SiO} 2 \mathrm{f} / \mathrm{SiO} 2$ composites. Materials and Manufacturing Processes. Vol. 31 (2016) No. 7, p. 887-895.

[7]. Zhang C, Feng P, Zhang J. Ultrasonic vibration-assisted scratch-induced characteristics of C-plane sapphire with a spherical indenter. International Journal of Machine Tools and Manufacture. Vol. 64 (2013) p. 38-48.

[8]. Lv D, Wang H, Tang Y, et al. Influences of vibration on surface formation in rotary ultrasonic machining of glass BK7. Precision Engineering. Vol. 37 (2013) No.4, p.839-848. 